\title{
CARTOGRAFIA PRELIMINAR DOS VÍNCULOS SOCIAIS NO PROCESSO MORADOR: MORADIA NO CONDOMÍNIO SÃO JOSÉ, ITABUNA, BA
}

\author{
Matheus Santos Silva* \\ Silvia Kimo Costa**
}

RESUMO: Este artigo apresenta os resultados da pesquisa intitulada: "Cartografia preliminar das relações sociais em condomínios Minha Casa Minha Vida em Itabuna, BA" que objetivou analisar o processo de desvínculos e revínculos sociais dos/das moradores/as em relação ao antigo local de morada e ao novo espaço de moradia, considerando: 1. laços sociais (re) existentes; 2 . a percepção quanto ao acesso a serviços urbanos básicos (farmácia, padaria, mercados, escolas, posto de saúde) e, 3. se há mobilidade social ascendente em função do novo espaço de moradia. Foi realizado um estudo de caso no conjunto habitacional condomínio São José, localizado a $10 \mathrm{~km}$ do centro urbano do município. Os dados foram coletados por meio da entrevista jornalística e registros de observação em diário de campo. Foi realizada a Análise de Conteúdo (AC) dos dados coletados. Os resultados mostraram que as relações de vizinhança são inevitáveis e imprescindíveis para manutenção dos vínculos sociais existentes com o local da antiga morada e para a apropriação da nova moradia; a distância do condomínio São José em relação a serviços urbanos, aliada à dificuldade de mobilidade urbana, corrobora o processo de exclusão socioespacial; entretanto, ter a propriedade do imóvel representa ascensão no status social para os/ as moradores/as do condomínio São José.

PALAVRAS-CHAVE: PMCMV; Lugar; Relações sociais; Moradia.

\section{PRELIMINARY CARTOGRAPHY OF THE SOCIAL BONDS IN THE DWELLER: DWELLING PROCESS IN THE HOUSING ESTATE SÃO JOSÉ, ITABUNA, BRAZIL}

ABSTRACT: Current essay is the result of a research work titled "Preliminary

\footnotetext{
"Bacharel Interdisciplinar em Humanidades. Discente do curso de 2o Ciclo de Formação em Direito da Universidade Federal do Sul da Bahia. Brasil.

** Doutora em Desenvolvimento e Meio Ambiente (UESC, BA. Docente Adjunto da Universidade Federal do Sul da Bahia, atuando no Instituto de Humanidades, Artes e Ciências e no Centro de Formação em Ciências Agroflorestais. Brasil. E-mail: skcosta@ufsb.edu.br
} 
cartography of the social bonds in condominiums Minha Casa Minha Vida in the town of Itabuna BA Brazil". The process of social de-bonding and re-bonding ties of dwellers with regard to their former dwelling place and the new one is analyzed. The following themes are discussed: 1 . re-existing social bonds; 2 . the perception of accessing basic urban services (pharmacy, bakery, shops, schools, health units); 3. whether there is an ascending social mobility within the new dwelling space. A case study was undertaken within the housing estate São José, some $10 \mathrm{~km}$ from downtown. Data were collected by a journalistic interview and observation reports in a field diary. A content analysis (CA) of data was undertaken. Results show that relationships with neighbors are basic to maintain already extant social bonds with the former dwelling place and for the appropriation of the new dwelling site and the distance of the estate with regard to urban services coupled to urban mobility corroborates the social and spatial exclusion process. However, the fact that the family is the owner of the house represents a rise in social status for the dwellers of the estate São José.

KEY WORDS: PMCMV; Place; Social relationships; Dwelling.

\section{INTRODUÇÃO}

O presente artigo apresenta os resultados da pesquisa intitulada: "Cartografia preliminar das relações sociais em condomínios Minha Casa Minha Vida (PMCMV) em Itabuna, BA" que objetivou analisar o processo de desvínculos e revínculos sociais dos/das moradores/as em relação ao antigo local de morada e ao novo espaço de moradia.

Considerou-se o "local de moradia" como aquele impregnado de valores, significados e processos de micro ritualizações. Ou seja, o locus do babitus de (re) construção da identidade social do/a morador/a. A pesquisa tomou como estudo de caso o conjunto habitacional condomínio São José vinculado ao PMCMV, localizado no município de Itabuna, Bahia.

A inquietação, que levou ao estudo, partiu de observações diárias do pesquisador durante o deslocamento via ônibus do centro urbano do município de Itabuna em direção ao campus Jorge Amado da Universidade Federal do Sul da Bahia, que se localiza em bairro periférico e próximo ao condomínio São José. 
Durante o processo de ir e vir, o pesquisador vivenciou, junto aos moradores do referido condomínio, a dificuldade quanto à mobilidade urbana e ao acesso a serviços urbanos tais como farmácias, supermercados, padarias, escolas, bancos, posto de saúde etc.

As técnicas de pesquisa utilizadas para coleta das informações foram entrevista jornalística aplicada a 15 famílias contempladas com um apartamento no conjunto habitacional condomínio São José, cujo cadastro na Secretaria de Assistência Social do município indicavam que eram provenientes de extrema vulnerabilidade habitacional, e registros de observação em diário de campo. Para análise das informações optou-se pelo método da Análise de Conteúdo (AC).

As informações coletadas permitiram analisar: 1. quais os laços (re) existentes entre as pessoas que moram no condomínio São José e o antigo local de morada destas; 2. a percepção quanto ao acesso a serviços urbanos básicos (farmácia, padaria, mercados, feiras, escolas, posto de saúde) e 3. se há mobilidade social ascendente em função do novo espaço de moradia.

$\mathrm{O}$ artigo encontra-se organizado em três partes. A primeira aborda os principais conceitos estudados para o desenvolvimento da pesquisa. A segunda descreve os procedimentos metodológicos para coleta e análise das informações e, a terceira apresenta os resultados e discussões.

\subsection{CONCEITOS NORTEADORES}

\subsubsection{Laços sociais, o lugar e o espaço de moradia}

De acordo com Portella \& Augustin (2012, p. 6), os laços sociais "fazem parte do sistema social, uma vez que conecta os atores individuais propiciando processos de interação entre estes". Os laços sociais iniciais estão presentes no convívio familiar e ampliam-se à medida que as pessoas interagem com diferentes grupos ao longo da vida. Entretanto, "a força de um laço não é medida unicamente em uma relação interpessoal, mas sim em um vínculo ao sistema social que torna possível ou não um conjunto de relações interpessoais que se inscrevem em esferas normativas distintas" (PAUGAM, 2017, p. 147). 
Ou seja, o sistema social possui uma normatização que faz com que as pessoas sejam coagidas a se conformar a ele para serem integradas (PAUGAM, 2017). Esse processo de conformação ao sistema social ocorre no vivenciar do dia a dia. Dessa forma, o dia a dia não é vivido como um cenário estático, mas como algo em constante movimento, em que são fundamentadas as relações espaciais diretas e articuladas à cooperação e ao conflito (MOREIRA \& HESPANHOL, 2007). O dia a dia inevitavelmente está atrelado ao lugar onde se vive, sendo assim o lugar é, antes de tudo, uma construção social.

Segundo Tuan (1983), o lugar é o espaço experienciado dotado de valor e significado. De acordo com Moreira \& Hespanhol (2007, p. 51), "o lugar é produto da experiência pessoal vivida, permeado de dimensões simbólicas, culturais, políticas e sociais" e "só adquire uma identidade e significado através das intenções humanas atribuídas a ele". E o lugar é impregnado de processos de micro ritualizações que constantemente o modificam. E ao modificar o lugar, o lugar modifica quem o vivencia (ITTELSON, 1978). Trata-se de um processo dialético.

O lugar é a porção do espaço apropriável para a vida - apropriada através do corpo - dos sentidos - dos passos de seus moradores, é o bairro é a praça, é a rua [...] a pequena vila ou cidade - vivida/ conhecida/ reconhecida em todos os cantos (CARLOS, 2007, p. 17 18).

Sendo assim, a mudança de um lugar para outro, sendo este outro a priore um novo espaço, implica tanto no desvínculo dos processos de micro ritualizações cotidianos em relação ao antigo lugar, como também no processo de viver, sentir, pensar e apropriar-se do novo espaço atribuindo-lhe valor e significado fazendo com que se torne um novo lugar (CARLOS, 2001). Mas o antigo lugar não perde os valores e significados que lhe foram atribuídos, pois os momentos vivenciados e os laços sociais ali construídos permanecem - há "apego ao lugar" (RYAN, 2005; VILLODRES, 1998), um vínculo afetivo.

Considerando o exposto é possível afirmar que o processo de mudança de um lugar (espaço dotado de valor, significado e de laços sociais) para um novo espaço (que ainda precisará ser sentido e apropriado pelo vivenciar para se tornar um lugar) é, em certa medida, impactante. A depender das relações interpessoais 
possibilitadas pelo vínculo social, esse impacto pode significar a ruptura com o antigo lugar ou um fortalecimento dos laços sociais com o mesmo.

É nesse limiar entre a ruptura com e o fortalecimento do lugar/ laços sociais que se propôs analisar como a rotina de estudos, trabalho, amizades e relações familiares de pessoas contempladas com um apartamento no condomínio São José vem sendo influenciada e/ ou modificada quanto aos vínculos que as mesmas possuíam com a antiga morada. E como a mobilidade urbana e acesso a serviços urbanos potencializam esse processo.

Nesse contexto, o pesquisador vivencia e se coloca como participante do processo "tecendo", por meio das técnicas de pesquisa para coleta dos dados, uma Cartografia das Subjetividades (PASSOS, et al. 2001). Essa cartografia possibilita ao pesquisador reconstituir uma realidade que se encontra em constante movimento, produzindo conhecimento por meio de suas percepções e sensações no encontro com seu campo (ROLNIK, 2011; ROMAGNOLI, 2009).

Pontua-se que a pesquisa considerou as pessoas que se enquadram no déficit habitacional na faixa de zero a três salários mínimos. Sendo que

O conceito de déficit habitacional utilizado está ligado diretamente às deficiências do estoque de moradias. Engloba aquelas sem condições de serem habitadas em razão da precariedade das construções ou do desgaste da estrutura física e que por isso devem ser repostas. Inclui ainda a necessidade de incremento do estoque, em função da coabitação familiar forçada (famílias que pretendem constituir um domicilio unifamiliar), dos moradores de baixa renda com dificuldades de pagar aluguel e dos que vivem em casas e apartamentos alugados com grande densidade. Inclui-se ainda nessa rubrica a moradia em imóveis e locais com fins não residenciais. O déficit habitacional pode ser entendido, portanto, como déficit por reposição de estoque e déficit por incremento de estoque (FUNDAÇÃO JOÃO PINHEIRO, 2016, p. 18).

Outro aspecto considerado foi o "lugar" como "espaço de moradia". Segundo Lemos (2010, p. 24), o "espaço de moradia se constitui no centro da existência humana com significações físicas, psicológicas e culturais, contendo uma familiaridade do mundo vivido, uma expressão da identidade sociocultural que reflete um status social e pertencimento". Outros fatores também afetam a relação 
morador/ espaço de moradia (seja o antigo ou o novo): aspectos físicos/construtivos da moradia; o uso social do espaço privado e coletivo e as relações de vizinhança (LEMOS, 2010).

Ou seja, as pessoas que se enquadram no déficit habitacional e que são contempladas com um novo espaço de moradia passam pela mudança não só de lugar (espaço vivido, sentido, dotado de valor e significado), mas também por uma reestruturação do sentimento de pertencimento, da identidade sociocultural e consequentemente do status social.

\section{METODOLOGIA}

DIÁRIO DE CAMPO: Itabuna, BA e o conjunto habitacional - condomínio São José

O município de Itabuna localiza-se no Estado da Bahia, na região conhecida como litoral sul próximo aos municípios de Ilhéus e Uruçuca (Figura 1). De acordo com o IBGE, em 2017, estimou-se que o município possuiria uma população equivalente a 221.046 mil habitantes. Segundo o Censo de 2010, a população correspondia a 204.667 mil habitantes, sendo que $97,5 \%$ são moradores da área urbana. Territorialmente, Itabuna ocupa cerca de $432,243 \mathrm{~km}^{2}$.

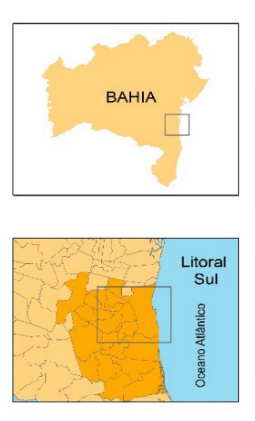

WGS 1934
Maio de 2014 -UESC

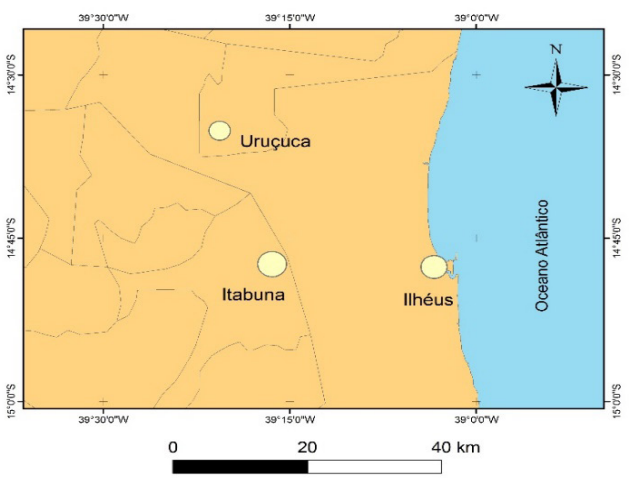

Figura 1. Localização do município de Itabuna, BA em relação ao litoral sul Fonte: Acervo pessoal de um dos autores (2014) 
De acordo com Ramos \& Noia (2014), em 2005, o déficit habitacional do referido município correspondia a 8.592 unidades habitacionais, sendo que cerca de 77,66\% desse valor eram referentes às famílias conviventes na área urbana; 17,19\% de pessoas vivendo em cômodos e 12,98\% em domicílios rústicos. Ainda segundo os autores, o déficit habitacional de Itabuna era composto em sua maior parte por famílias cuja renda mensal não ultrapassava três salários mínimos. Além disso, no que se refere à inadequação habitacional em Itabuna,

$\mathrm{O}$ indicador de maior destaque é a carência de infraestrutura, ou seja, o domicílio não dispõe de ao menos um dos serviços básicos (iluminação elétrica, rede geral de abastecimento de água com canalização interna, rede geral de esgoto sanitário ou fossa séptica e coleta de lixo), configurando um total de 11.410 unidades habitacionais (RAMOS; NOIA, 2014, p. 8).

Considerando tal diagnóstico habitacional, Ramos e Noia (2014) destacam que, em 2011, a Caixa Econômica Federal contratou cerca de $\mathrm{R} \$ 140.524 .335,85$ para execução de obras do PMCMV, em Itabuna, sendo que, em 2014, o valor contratado foi acrescido, totalizando um investimento de $\mathrm{R} \$ 380.078 .122,42$.

Sendo assim, foram construídos e entregues, desde 2012, nove empreendimentos no município: os conjuntos habitacionais Pedro Fontes 1 e 2; os conjuntos habitacionais Jardim América 1 e 2; o conjunto habitacional Vida Nova; o conjunto habitacional (condomínio) São José; o conjunto habitacional Jubiabá; o conjunto habitacional Gabriela e o Itabuna Parque. E, em 2019, está prevista a inauguração do conjunto habitacional Jorge Amado.

O conjunto habitacional - condomínio São José, local da pesquisa, localiza-se às margens da BR 415 (rodovia Itabuna - Vitória da Conquista, BA), bairro Ferradas, no município de Itabuna, BA, e dista cerca de $10 \mathrm{~km}$ do centro urbano (Figura 2). 


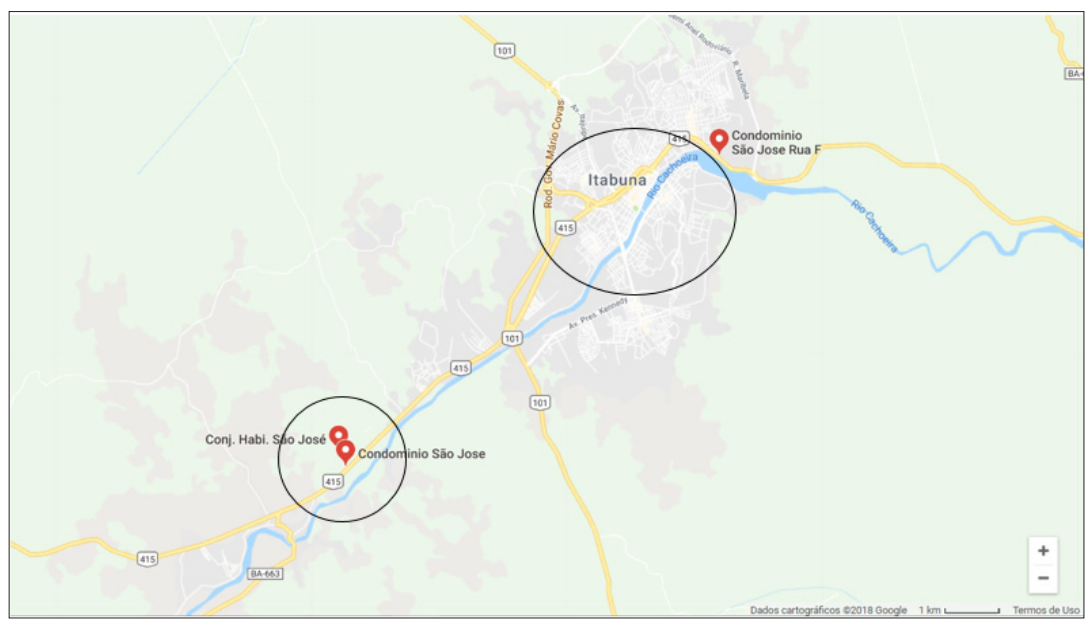

Figura 2. Localização do conjunto habitacional - condomínio São José em relação ao centro urbano do município de Itabuna, BA Fonte: Google Earth 2018 (on-line)

O conjunto habitacional condomínio São José (Figuras 3 e 4) foi construído em blocos de oito apartamentos e projetado para atender famílias de baixa renda inscritas no PMCMV pela prefeitura de Itabuna, por meio da Secretaria Municipal de Assistência Social. Cada apartamento possui sala, cozinha, dois quartos e banheiro, totalizando área útil de $39,00 \mathrm{~m}^{2}$.

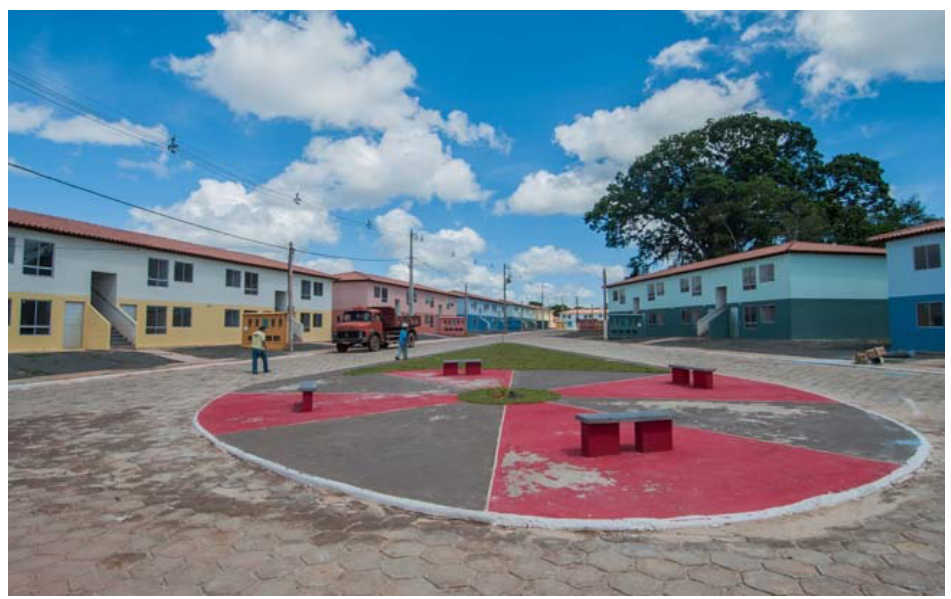

Figura 3. Conjunto habitacional - condomínio São José, Itabuna, BA Crédito da foto: Gabriel de Oliveira (2016), Itabuna, BA. 


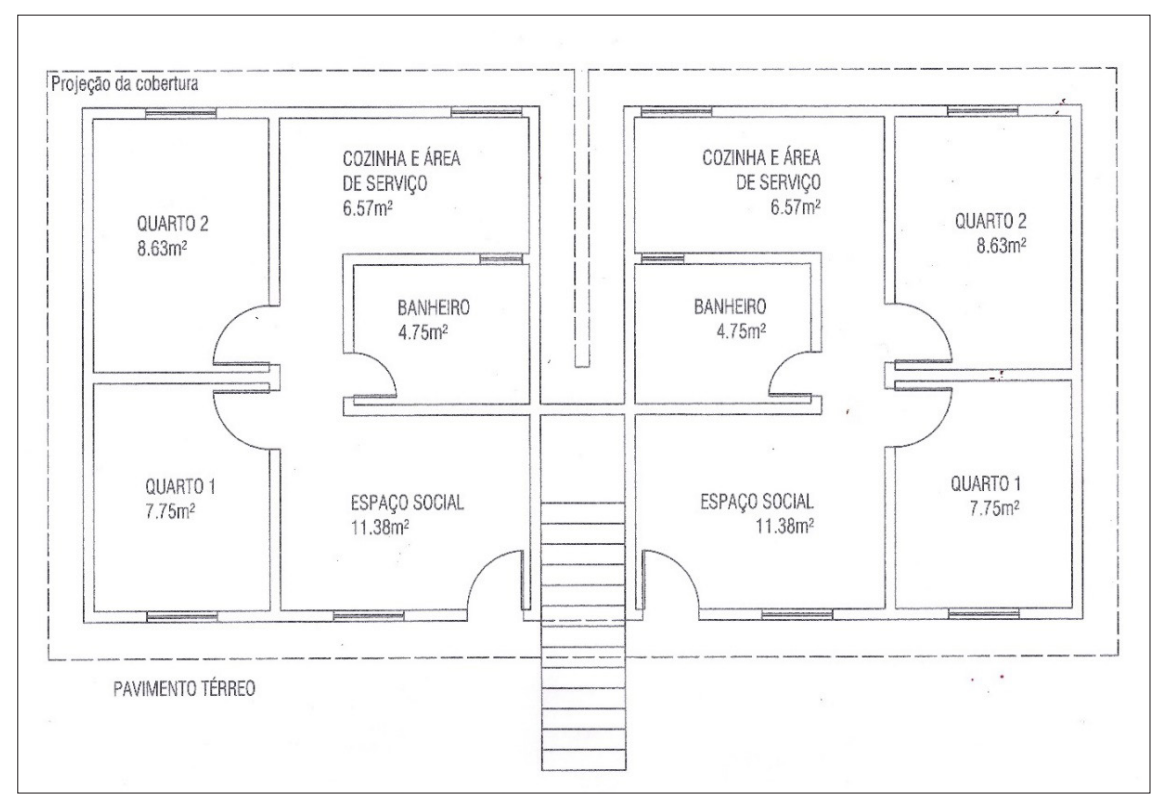

Figura 4. Planta baixa de dois apartamentos do conjunto habitacional - condomínio São José, Itabuna, BA Fonte: Elaborado pelos autores.

DIÁRIO DE CAMPO: observação, entrevista jornalística e amostragem

Para coleta das informações no condomínio São José consideraram-se três procedimentos: o primeiro diz respeito aos registros em diário de campo considerando a observação participante uma vez que "as pessoas da comunidade estudada aceitam a presença do pesquisador entre eles como um vizinho e amigo [...] e não simplesmente como um cientista" (AGROSINO, 2009, p. 63).

$\mathrm{O}$ segundo procedimento diz respeito à obtenção das informações quanto ao vivenciar dos moradores no condomínio São José e o vivenciar na antiga morada. Sendo assim, optou-se pela "entrevista jornalística" (CAPUTO, 2006) composta por quatro perguntas elaboradas a partir dos objetivos específicos da pesquisa (Quadro 1): 
Quadro 1. Síntese dos objetivos específicos da pesquisa e das perguntas do roteiro de entrevista em relação a cada objetivo específico

\begin{tabular}{|l|l|}
\hline Objetivos específicos & Perguntas referentes a cada objetivo \\
\hline $\begin{array}{l}\text { 1. Perceber e identificar os tipos de vínculos } \\
\text { sociais que existiam e/ ou que ainda existem na } \\
\text { antiga morada e os construídos no condomínio } \\
\text { São José. }\end{array}$ & $\begin{array}{l}\text { 1. Você ainda tem familiares, amigos, e/ ou } \\
\text { mantém atividades de trabalho, estudos e } \\
\text { outras atividades em comunidade no seu } \\
\text { antigo lugar de morada? }\end{array}$ \\
$\begin{array}{l}\text { 2. Como é seu relacionamento com os } \\
\text { vizinhos aqui no condomínio São José? Você } \\
\text { fez novos amigos? }\end{array}$ \\
\hline $\begin{array}{l}\text { 2. Identificar os impactos-benefíciose malefícios } \\
\text { - para os moradores em relação ao novo espaço } \\
\text { de moradia considerando mobilidade urbana } \\
\text { e acesso a serviços urbanos (farmácia, escolas, } \\
\text { padaria, mercado, posto de saúde). }\end{array}$ & $\begin{array}{l}\text { 3. O que você achou de bom e de ruim } \\
\text { Juando passou a morar no condomínio São }\end{array}$ \\
\hline $\begin{array}{l}\text { 3. Compreender as representações simbólicas } \\
\text { de mobilidade social ascendente com o novo } \\
\text { espaço de moradia. }\end{array}$ & $\begin{array}{l}\text { 4. O que significa para você viver no } \\
\text { condomínio São José? }\end{array}$ \\
\hline
\end{tabular}

Fonte: Elaborado pelos autores

E o terceiro procedimento envolveu a delimitação da amostragem (pessoas a serem entrevistadas). Para estimar quantas pessoas deveriam ser entrevistadas, consideraram-se os seguintes critérios:

1. O cadastro na prefeitura do município de Itabuna, BA das pessoas que foram contempladas com um apartamento no conjunto habitacional São José com renda salarial entre zero a três salários mínimos;

2. dentro do cadastro, quais eram as famílias que se enquadravam nos critérios estipulados pela Fundação João Pinheiro (2016) no que se refere ao déficit habitacional quantitativo;

3. considerando os critérios estipulados pela Fundação João Pinheiro (2016) no que se refere ao déficit habitacional quantitativo, quais eram as famílias que se encontravam em maior estado de vulnerabilidade habitacional?; 
4. a metodologia de análise constou das informações pautadas na análise de conteúdo com base no roteiro de entrevista jornalística e transcrição das mesmas.

Sendo assim, foram escolhidas 15 famílias para a pesquisa e foram entrevistados/as seus/suas respectivos/as chefes. As entrevistas ocorreram entre os dias 20 de dezembro de 2017 e 05 de janeiro de 2018; foram gravadas (apenas áudio) e posteriormente transcritas fielmente de acordo com as respostas dos/das entrevistados/as.

\section{DIÁRIO DE CAMPO: Análise de conteúdo}

Segundo Caregnato e Mutti (2006, p. 682), a análise de conteúdo considera o texto como "um meio de expressão do sujeito, onde o analista busca categorizar as unidades de texto (palavras ou frases) que se repetem, inferindo uma expressão que as representem". A análise de conteúdo trabalha com textos que podem ser provenientes de pesquisas, pela transcrição de entrevistas e de protocolos de observação. Segundo as autoras, a AC é composta por três grandes etapas:

\footnotetext{
1) pré-análise; 2) exploração do material;3) tratamento dos resultados e interpretação [...] a primeira etapa como a fase de organização, que pode utilizar vários procedimentos, tais como: leitura flutuante, hipóteses, objetivos e elaboração de indicadores que fundamentem a interpretação. Na segunda etapa os dados são codificados a partir das unidades de registro. Na última etapa se faz a categorização, que consiste na classificação dos elementos segundo suas semelhanças e por diferenciação, com posterior reagrupamento, em função de características comuns. Portanto, a codificação e a categorização fazem parte da AC (CAREGNATO; MUTTI, 2006, p. 683).
}

Considerando o exposto, foram transcritas as entrevistas dos/das 15 chefes de família moradores/as do conjunto habitacional São José. Após a transcrição, palavras/ frases-chave que sintetizavam as respostas dadas a cada pergunta foram extraídas e tabuladas. As palavras/frases-chave foram organizadas, em função de cada objetivo específico da pesquisa/ perguntas do roteiro de entrevista jornalística, num 
quadro matriz. Esse quadro matriz foi construído para cada um dos três objetivos específicos.

\section{RESULTADOS E DISCUSSÃO}

\subsection{A APROPRIAÇÃO DO NOVO ESPAÇO DE MORADIA}

De acordo com Lemos (2010, p. 24), "a casa representa a própria imagem do dono e, portanto, incluem nela um sistema de valores sociais e morais". Existe a casa e existe a vizinhança da casa, esses dois aspectos constituem o "espaço de moradia".

A construção das relações sociais com a vizinhança implica em

[...] trocas no plano das vivências, de sentimentos, comportamentos e percepções. A vida é construída em conjunto com o outro, com o coletivo compartilhado na rotina do fazer. É através das mesmas que há superação das necessidades, e da reafirmação do posicionamento frente do vivido. As relações de vizinhança têm uma estreita relação com o cotidiano do indivíduo, sendo um comportamento social aceito e praticado durante toda existência humana (LEMOS, 2010, p. 25).

A casa e as relações de vizinhança (espaço de moradia) contribuem para a construção da identidade social de todos aqueles os vivenciam cotidianamente. Tratase de um espaço plural onde o habitus é um princípio de correspondência entre as práticas individuais e as condições sociais de existência, duráveis e transponíveis integrando todas as experiências passadas e orientando as futuras (BOURDIEU, 1983). Assim, deixar um espaço de moradia e se apropriar de um novo espaço de moradia implica no babitus de (re) construção da identidade social. Esse processo foi observado no condomínio São José não só durante as entrevistas com os/as 15 chefes de família, mas também durante o vivenciar do local por parte do pesquisador.

Sendo assim, ao "perceber e identificar os tipos de vínculos sociais que existiam e/ ou que ainda existem na antiga morada e os construídos no Condomínio 
São José” (objetivo específico 1 da pesquisa) (Quadro 2), constatou-se que os vínculos com o antigo lugar permanecem, pois, familiares e amigos continuam morando no lugar da antiga morada, as relações de vizinhança foram reduzidas, mas continuam estabelecidas. E ao mesmo tempo novos vínculos vêm sendo construídos com o novo espaço de moradia.

Apesar de estarem envoltos cada qual em suas histórias particulares de vida, a apropriação do novo espaço implica no estabelecimento de novas relações de vizinhança, na constituição de uma comunidade local e no desenvolvimento de atividades afins.

Quadro 2. Matriz de palavras/ frases-chave extraídas da transcrição das entrevistas em relação ao objetivo específico 1

\begin{tabular}{|c|c|c|c|}
\hline Objetivos específicos & Perguntas & $\begin{array}{c}\text { Palavras/ frases- } \\
\text { chave }\end{array}$ & Quant. \\
\hline \multirow{8}{*}{$\begin{array}{l}\text { Perceber e identificar os } \\
\text { tipos de vínculos sociais } \\
\text { que existiam e/ ou que } \\
\text { ainda existem na antiga } \\
\text { morada e os construídos } \\
\text { no condomínio São José }\end{array}$} & \multirow{4}{*}{$\begin{array}{l}\text { 1. Você ainda tem familiares, } \\
\text { amigos, e/ ou mantém atividades } \\
\text { de trabalho, estudos e outras } \\
\text { atividades em comunidade no } \\
\text { seu antigo lugar de morada? }\end{array}$} & $\begin{array}{ll}\text { "A } & \text { igreja } \\
\text { congrego é lá" } & \end{array}$ & 7 \\
\hline & & $\begin{array}{l}\text { "Lá tínhamos família, } \\
\text { parentes" }\end{array}$ & 8 \\
\hline & & $\begin{array}{l}\text { "amigos a vizinhança } \\
\text { toda" }\end{array}$ & 13 \\
\hline & & $\begin{array}{l}\text { "muito tempo } \\
\text { morando lá" }\end{array}$ & 4 \\
\hline & \multirow{4}{*}{$\begin{array}{l}\text { 2. Como é seu relacionamento } \\
\text { com os vizinhos aqui no } \\
\text { condomínio São José? Você fez } \\
\text { novos amigos? }\end{array}$} & $\begin{array}{l}\text { "o convívio é } \\
\text { s u per t ra nquilo, } \\
\text { existem vários } \\
\text { amigos" }\end{array}$ & 6 \\
\hline & & $\begin{array}{l}\text { "amigos não só } \\
\text { conhecidos" }\end{array}$ & 4 \\
\hline & & $\begin{array}{l}\text { "os que conheço, já } \\
\text { tenho muita amizade" }\end{array}$ & 3 \\
\hline & & $\begin{array}{l}\text { "Não porque não sou } \\
\text { muito de amigo não" }\end{array}$ & 1 \\
\hline
\end{tabular}

Fonte: Elaborado pelos autores 
Ao buscar "identificar os impactos - benefícios e malefícios - para os moradores em relação ao novo espaço de moradia, considerando mobilidade urbana e acesso a serviços urbanos (farmácia, escolas, padaria, mercado, posto de saúde)" (objetivo específico 2 da pesquisa) (Quadro 3), observou-se que a maioria dos entrevistados reclamou da distância do condomínio São José em relação ao centro do município (cerca de $10 \mathrm{~km}$ ) e a supermercados, bancos, farmácia; havendo a dependência constante do ônibus.

Rangel e Thevenin (2018) apontam que a construção de conjuntos habitacionais distantes do centro do município não só de Itabuna, mas também de Ilhéus, vem provocando um esgarçamento do tecido urbano, constituindo núcleos separados por vazios intersticiais. Segundo Souza \& Sugai (2018); Rubin (2013), isso evidencia a contradição entre o objetivo do Programa Minha Casa Minha Vida de atender o déficit habitacional brasileiro (que envolve aspectos quantitativos e de qualidade da habitação) e o processo de segregação espacial e de exclusão social e territorial corroborado pelo mesmo.

Durante as visitas para a coleta dos dados, o pesquisador relata em seu diário de campo que observou a quantidade de ônibus coletivos disponíveis e o intervalo entre um e outro no trajeto do centro de Itabuna ao condomínio São José: "levou-se em média cerca de uma hora de espera no ponto de ônibus e quarenta minutos do condomínio até o centro da cidade. Ou seja, são quase quatro horas diárias no processo de ir e vir". 
Quadro 3. Matriz de palavras/ frases-chave extraídas da transcrição das entrevistas em relação ao objetivo específico 2

\begin{tabular}{|c|c|c|c|}
\hline Objetivos específicos & Perguntas & Palavras/frases-chave & Quant. \\
\hline \multirow{3}{*}{$\begin{array}{l}\text { Identificar os impactos - } \\
\text { benefícios e malefícios - para } \\
\text { os moradores em relação } \\
\text { ao novo espaço de moradia, } \\
\text { considerando a mobilidade } \\
\text { urbana e acesso a serviços } \\
\text { urbanos (farmácia, escolas, } \\
\text { padaria, mercado, posto de } \\
\text { saúde) }\end{array}$} & \multirow{3}{*}{$\begin{array}{l}\text { 3. O que você achou de } \\
\text { bom e de ruim quando } \\
\text { passou a morar no } \\
\text { condomínio São José? }\end{array}$} & $\begin{array}{l}\text { Positivo - "existe maior } \\
\text { liberdade" }\end{array}$ & 15 \\
\hline & & $\begin{array}{l}\text { Positivo - "A casa é } \\
\text { minha, tá no meu } \\
\text { nome, ninguém toma" }\end{array}$ & 15 \\
\hline & & $\begin{array}{l}\text { Negativo - } \text { "pra } \\
\text { tudo tem que pegar } \\
\text { condução, ir no } \\
\text { mercado, no banco, na } \\
\text { farmácia..." }\end{array}$ & 9 \\
\hline
\end{tabular}

Fonte: Elaborado pelos autores

Entretanto, apesar da dificuldade de mobilidade e distância de serviços urbanos básicos foi unânime a satisfação de ter "condições dignas" de moradia.

O/a entrevistado/a $\mathrm{n}^{07}$ afirma: "Positivo porque a casa é própria, lá não era própria onde eu morava". O mesmo pode ser constatado no depoimento do/a entrevistado/a $\mathrm{n}^{\circ} 11$ : "Aqui tem muita diferença porque a casa é minha mesmo, eu gosto do local".

Muitos conviviam com dificuldades financeiras para pagar o aluguel. O/a entrevistado/a $\mathrm{n}^{\circ} 14$ explica: "Aqui é melhor porque lá eu tava pagando uma coisa que não era minha e aqui eu tô pagando uma coisa que é meu, pagava um mês devendo o outro, aluguel já sabe". O/a entrevistado/a n4 confirma: "O positivo é que a casa é minha, aqui eu pagando ninguém toma, é meu, se atrasar alguma conta eu sei que é meu, ninguém vem pra minha porta cobrar ou bater".

Outros viviam em habitações precárias, sem o mínimo de conforto e localizadas em bairros carentes de infraestrutura urbana (sem calçamento; sem iluminação pública de qualidade; sem drenagem de águas pluviais; sem coleta de lixo e o esgoto sanitário correndo a céu aberto). O/a entrevistado/a n 10 relata:

Minha vida mudou pra melhor, aqui eu estou na minha casa né, as condições físicas da casa aqui são totalmente diferentes, aqui tudo é planozinho, tudo é [...] a casa é estruturada boa, é pequena é, 
lá era onde eu morava era maior, mas o chão não era, um lado era piso e outro não era, molhava tudo! A rua era feinha, tinha dia que chovia tinha dia que a água entrava pra dentro de casa, tinha que está secando, entendeu! O fundo não era bonzinho, tinha que descer escada, aqui o ruim só é a água também de vez em quando, de vez em quando a água falta, principalmente pra quem não tem tanque, só tá me faltando aqui é um tanque, vai fazer dois dias sem água, mas a casa é boa, uma moradia também boa, os vizinhos também são ótimos.

Alguns dos/as entrevistados/as viviam na casa dos pais e o apartamento no condomínio São José representou liberdade, conforto e independência. Segundo O/a entrevistado/a $n^{\circ}$ 2: "Até o momento é positivo porque eu morava em casa de parentes, aqui a gente tem mais uma liberdade, hoje tem mais uma liberdade do que anteriormente $[\ldots] "$.

Quanto à "compreensão das representações simbólicas de mobilidade social ascendente com o novo espaço de moradia" (objetivo específico 3 da pesquisa) (Quadro 4), ficou evidente que ser proprietário de um apartamento no condomínio São José tornou-se sinônimo de um novo status social. 
Quadro 4. Matriz de palavras/ frases-chave extraídas da transcrição das entrevistas em relação ao objetivo específico 3

\begin{tabular}{|c|c|c|c|}
\hline Objetivos específicos & Perguntas & Palavras/ frases-chave & Quant. \\
\hline \multirow{7}{*}{$\begin{array}{l}\text { Compreender as } \\
\text { representações } \\
\text { simbólicas de } \\
\text { mobilidade social } \\
\text { ascendente com } \\
\text { o novo espaço de } \\
\text { moradia }\end{array}$} & \multirow{7}{*}{$\begin{array}{l}40 \text { que significa } \\
\text { para você viver } \\
\text { no condomínio } \\
\text { São José? }\end{array}$} & $\begin{array}{l}\text { "Viver sobre pressão, em concordância } \\
\text { com outro" }\end{array}$ & 6 \\
\hline & & $\begin{array}{l}\text { "não posso falar abertamente tudo } \\
\text { que quero por causa da proximidade" }\end{array}$ & 2 \\
\hline & & "Qualidade do entorno" & 2 \\
\hline & & "Lugar mais solitário" & 4 \\
\hline & & "Segurança e privacidade" & 4 \\
\hline & & $\begin{array}{l}\text { "Consegui a casa própria, boa para } \\
\text { morar" }\end{array}$ & 9 \\
\hline & & $\begin{array}{l}\text { "Vizinhos não respeitam o espaço do } \\
\text { outro" }\end{array}$ & 1 \\
\hline
\end{tabular}

Fonte: elaborado pelos pesquisadores

\section{O/a entrevistado/a $\mathrm{n}^{\circ} 6$ confirma que}

Aqui pra mim é como se o camarada subisse um degrau, lá a casa não dava condições nenhuma pra viver dentro dela, um barraco tanto que uma parede coberta de plástico pra não entrar água pra sala e só tinha um quarto né e quando chovia a água do campo passava pra dentro, a casa aqui hoje tá em outras condições de vida, moradia é tudo; pra minha idade tenho 62 anos de idade, da outras condições de vida $[\ldots]$

Entretanto, apesar de aspectos positivos tais como estrutura da habitação, segurança, organização, privacidade, limpeza e comodidade, os/as entrevistados/as caracterizaram o condomínio São José como um ambiente fechado por muros que promove o isolamento e individualismo excessivo. Além disso, alguns relataram que experienciaram desavenças com vizinhos em relação ao uso dos espaços comuns. Os/as entrevistados/as afirmaram que há interação social baseada na amizade, na coletividade, no afeto e solidariedade, mas também há aqueles que preferem não interagir. 
Durante as entrevistas e nas observações in loco foi possível perceber que, ao mesmo tempo em que há a separação individualista, há o coletivismo para compartilhar experiências e histórias. O coletivismo ocorre nos ambientes de convívio comum do condomínio: nas ruas entre os blocos de apartamentos, nos pátios, na quadra de esportes e na praça. Mas é indubitável que a cooperação coletiva e o apego ao lugar são maiores nas ruas dos bairros de onde são provenientes os moradores do que na copropriedade do condomínio São José.

Outro aspecto observado foi o processo de adaptação dos moradores ao regulamento de convivência do conjunto habitacional. $\mathrm{O} / \mathrm{a}$ entrevistado/a $\mathrm{n}^{\circ} 4$ relata:

[...] tem muitas coisas aqui que você vive sobre pressão, quer fazer uma coisa já tem que concordar com o outro se pode ou não, tem isso de condomínio, as vezes você tem interesse de fazer umas coisas o vizinho já não quer, o outro já não concorda, a zuada por exemplo eu não gosto muito, mas já peguei um vizinho que gosta de zuada, como tenho menino pequeno às vezes ultrapassa o limite a gente vai reclamar eles falam que entendeu... tem a porta aí embaixo quando minhas meninas descem eles reclamam da zuada que minhas meninas tão fazendo zuada, mas quando são eles, eles não acham que estão incomodando. Então tá tendo essa dificuldade aqui (...).

O acesso à cidade é fator primordial para manutenção de moradores em uma determinada área, mas o solo provido de infraestrutura e serviços urbanos possui custo elevado. Entretanto, o Poder Público precisa atender o déficit habitacional em conformidade com a Constituição Federal (BRASIL, 1988), Emenda Constitucional no 26/00, Artigo 60 ${ }^{\circ}$, caput: "São direitos sociais a educação, a saúde, a alimentação, o trabalho, a moradia, o lazer, a segurança, a previdência social, a proteção à maternidade e à infância, a assistência aos desamparados, na forma desta Constituição."

Dessa forma, o Programa Minha Casa Minha Vida, assim como tantos outros programas habitacionais anteriores, objetiva atender a Constituição Federal. Porém, o Poder Público continua priorizando a construção dos conjuntos habitacionais distantes dos centros urbanos contribuindo para manter a segregação espacial e aprofundar a exclusão social e territorial (COTA; SILVA, 2016; LOPES, ABDALLA; ZAMBRANO, 2015). Essa realidade é visível no condomínio São José, mas, apesar 
disso, os moradores vivenciam, sentem e apropriam-se do novo espaço de moradia de forma intensa, atribuindo-lhe valor e significado.

\section{CONCLUSÃO}

A pesquisa possibilitou dar voz a algumas famílias (provenientes de intensa situação de vulnerabilidade habitacional), que foram contempladas em um dos empreendimentos do Programa Minha Casa Minha Vida, no município de Itabuna, BA - o conjunto habitacional condomínio São José. Na escuta dessas vozes, procurou-se compreender como se deu a mudança de um espaço de moradia (lugar impregnado de micro ritualizações e valores) para um novo espaço, sendo este último passível de ser significado a partir do processo de apropriação do mesmo.

Considerando o desvínculo ou não das relações sociais existentes com o antigo lugar de morada e a construção de vínculos com o novo espaço de moradia, buscou-se observar a rotina das famílias escolhidas para a pesquisa. Para tanto foi necessário: 1. perceber e identificar os tipos de vínculos sociais que existiam e/ ou que ainda existem na antiga morada e os construídos no condomínio São José; 2. identificar os impactos - benefícios e malefícios - para os moradores em relação ao novo espaço de moradia considerando mobilidade urbana e acesso a serviços urbanos (farmácia, escolas, padaria, mercado, posto de saúde); e 3. compreender as representações simbólicas de mobilidade social ascendente com o novo espaço de moradia.

Os resultados mostraram que: a) a apropriação do novo espaço de moradia implica no estabelecimento de novas relações de vizinhança; b) o apego ao antigo lugar de morada, a redução da convivência contínua com familiares e com grupos sociais específicos, não foi superior à satisfação de ter "condições dignas" de moradia e c) ter a propriedade do imóvel representa uma ascensão no status social.

O condomínio São José é similar aos demais empreendimentos do Programa Minha Casa Minha Vida no que se refere à distância do conjunto habitacional em relação a serviços urbanos tais como: farmácias, padarias, bancos, feira livres, supermercados e escolas. Esse fato foi pontuado como aspecto negativo por parte 
das famílias entrevistadas durante a pesquisa. Entretanto, a satisfação em ter a propriedade do imóvel é maior do que a insatisfação com a distância do mesmo em relação ao centro da cidade.

Essa constatação não implica em corroborar com a continuidade de construção de tais empreendimentos desagregados do tecido urbano provido de infraestrutura e serviços. Se os conjuntos habitacionais vinculados ao PMCMV e/ ou a outros programas, representam, em certa medida, o cumprimento da Constituição Federal no que tange garantir o direito de todos a uma moradia digna e de qualidade, urge impedir que tais empreendimentos continuem materializando a segregação espacial e a exclusão social e territorial.

\section{REFERÊNCIAS}

ANGROSINO, M. Etnografia e observação participante. Porto Alegre: Artmed, 2009.

BOURDIEU, P. Questões de Sociologia. Rio de Janeiro: Marco Zero, 1983.

BRASIL. Constituição da República Federativa do Brasil. Brasília, DF: Senado Federal, 1988.

CAREGNATO, R. C. A.; MUTTI, R. Pesquisa Qualitativa: análise de discurso versus análise de conteúdo. Texto Contexto Enferm, v. 15, n. 4, p. 679-684, 2006. Disponível: http://www.scielo.br/pdf/tce/v15n4/v15n4a17. Acesso em: 25/04/2018.

CARLOS, A. F. A. O lugar no/do mundo. São Paulo: FFLCH, 2007.

CARLOS, A. F. A. Espaço-Tempo na Metrópole: a fragmentação da vida cotidiana. São Paulo: Contexto, 2001.

CAPUTO, S. G. Sobre entrevistas: teoria, prática e experiências. Petrópolis, RJ: Editora Vozes, 2006.

COTA, D. A.; SILVA, A. L. A. Programa "Minha Casa, Minha Vida" (faixa 1) em São João Del Rei, MG: uma análise crítica. Revista do Programa de Pós-Graduação 
em Geografia, v. 8, n. 2, p. 140-162, 2016. Disponível: < http://eduem.uem.br/ laboratorio/ojs/index.php/Geoinga/article/viewFile/37951/19710>. Acesso em: $10 / 03 / 2018$.

FUNDAÇÃO JOÃO PINHEIRO. Déficit habitacional no Brasil 2013-2014. Belo Horizonte: Fundação João Pinheiro - Centro de Estatística e Informações, 2016.

IBGE - INSTITUTO BRASILEIRO DE GEOGRAFIA E ESTATÍSTICA, Brasil: Censo 2010. Disponível: http://www.ibge.gov.br/home. Consultado em: 25/04/2018.

ITTELSON, W. H. Environmental Perception and Urban Experience. Environment and Behavior, v. 10, n. 2, p. 193-213, 1978. DOI: https://doi. org/10.1177/0013916578102004

LEMOS, J. de A. Vivendo a transição de ambiente de moradia: um estudo com moradores do Parque Residencial Manaus - PROSAMIM. Dissertação de Mestrado em Ciências do Ambiente. Manaus, 2010. Disponível: http://ppgcasa.ufam.edu.br/ pdf/dissertacoes/2010/Janeth\%20de\%20Araujo.pdf. Acesso em: 25/04/2018.

LOPES, I. C.; ABDALLA, J. G. F.; ZAMBRANO, L. M de A. Práticas sociais e o modo de uso efetivo pelo habitante - avaliação empírica em empreendimento MCMV. In: IV Simpósio Brasileiro de Qualidade do Ambiente Construído. Anais do IV Simpósio Brasileiro de Qualidade do Ambiente Construído, p. 1-12, 2015. Disponível: http://www.locus.ufv.br/bitstream/handle/123456789/6061/91.pdf?sequence $=3$. Acesso em: 10/03/2018.

MOREIRA, E. V.; HESPANHOL, R. A. de M. O Lugar como uma construção social. Revista Formação, v. 2, n. 14, p. 48-60, 2007. Disponível: http://revista.fct.unesp.br/ index.php/formacao/article/view/645. Acesso em: 10/03/2018.

PASSOS, E.; KASTRUP, V.; ESCÓSSIA, L. Pistas do Método da Cartografia: pesquisaintervenção e produção de subjetividade. Porto Alegre: Sulina, Editora da UFRGS, 2010.

PAUGAM, S. Durkheim e o vínculo aos grupos: uma teoria social inacabada. Sociologias, n. 44, p. 128-160, 2017. DOI: http://dx.doi.org/10.1590/15174522019004405 . 
RANGEL, M. C.; THEVENIN, J. M. R. Para além da crise cacaueira - a expansão dos condomínios fechados em Ilhéus BA: uma análise preliminar da cidade estendida. Revista do Programa de Pós-Graduação em Geografia, v. 10, n. 1, p. 59-83, 2018. Disponível: $\quad<$ http://eduem.uem.br/laboratorio/ojs/index.php/Geoinga/article/ view/40064/20892. Acesso em: 12/09/2018.

RAMOS, J. da S.; NOIA, A. C. Análise da execução do Programa Minha Casa Minha Vida nos municípios de Ilhéus e Itabuna, Bahia. In: IV Semana do Economista \& IV Encontro de Egressos. Anais da IV Semana do Economista \& IV Encontro de Egressos - GT1 Economia Regional e Baiana, p. 1-20, 2014.

ROLNIK, S. Cartografia Sentimental: transformações contemporâneas do desejo. Porto Alegre: Sulina, Editora da UFRGS, 2011.

ROMAGNOLI, R. C. A Cartografia e a relação pesquisa e vida. Revista Psicologia \& Sociedade, v. 21, n. 2, p. 166-173, 2009. Disponível: http://www.scielo.br/pdf/psoc/ v21n2/v21n2a03. Acesso em: 10/03/2018.

RYAN, R. L. Exploring the effects of Environmental Experience on attachment to Urban Natural Areas. Environment and Behavior, v. 37, n. 3, p.1-41, 2005. DOI: https://doi.org/10.1177/0013916504264147.

RUBIN, G. R. Movimento Moderno e habitação social no Brasil. Geografia Ensino \& Pesquisa, v. 17, n. 2, p. 57-71, 2013. DOI: 10.5902/2236499410772.

SOUZA, E. L.; SUGAI, M. I. Minha Casa Minha Vida: periferização, segregação e mobilidade intraurbana na área conurbada de Florianópolis. Cad. Metrop., v. 20, n. 41, p. 75-98, 2018. DOI: http://dx.doi.org/10.1590/2236-9996.2018-4104

TONDOLO, R. da R. P.; AUGUSTIN, R. O papel dos laços sociais na constituição do capital social. Contribuciones a las Ciencias Sociales, p. 1-10, 2012. Disponível: https://ideas.repec.org/a/erv/coccss/y2012i2012-1114.html. Consultado em: 10/03/2018.

TUAN, Y. F. Espaço e Lugar: a perspectiva da experiência. São Paulo: Difel, 1983.

VILLODRES, M. C. H. Apego al lugar: ambitos, dimensiones y estilos. Tese de Doutorado em Psicología Cognitiva, Social y Organizacional. Espanha, 1998. 
Disponível: https://riull.ull.es/xmlui/handle/915/10067. Acesso em: 10/03/2018.

Recebido em: 06/11/2018

Aceito em: 30/11/2018 